\title{
Aspergillus pseudodeflectus: a new human pathogen in liver transplant patients
}

\author{
Nawel Aït-Ammar ${ }^{1,2}$, Eric Levesque ${ }^{3}$, Jean-Benjamin Murat ${ }^{1,2}$, Sébastien Imbert ${ }^{4}$, Françoise Foulet ${ }^{1}$,
} Eric Dannaoui ${ }^{2,5}$ and Françoise Botterel ${ }^{1,2^{*}}$ (D)

\begin{abstract}
Background: Liver transplant recipients are at high risk of developing invasive aspergillosis and in particular by Aspergillus fumigatus which is the most commonly encountered species in this population. Other non-fumigatus Aspergillus species with reduced susceptibility to antifungal drugs can also be involved. Accurate identification associated to antifungal susceptibility testing is essential for therapy adjustment. We report a case of invasive pulmonary aspergillosis due to Aspergillus pseudodeflectus in a liver transplant recipient. To our knowledge, this is the first reported case of invasive aspergillosis due to this species with a reduced susceptibility to azoles.
\end{abstract}

Case presentation: A 64 year-old woman with drug-induced fulminant hepatitis underwent liver transplantation. Prophylactic treatment with caspofungin was introduced due to aspergillosis risk factors consisting in hemodialysis and fulminant hepatitis. Six weeks after transplantation, CT scan showed a right pulmonary opacity associated with an increase of galactomannan (index 5.4). Culture of BAL grew with several colonies of Aspergillus sp. The diagnosis of invasive aspergillosis was probable according to the EORTC criteria. The antifungal susceptibility tests (Etest ${ }^{\oplus}$ ) revealed low MICs to echinocandins and amphotericin B) but high MICs to azoles. After these results, voriconazole was switched to liposomal amphotericin B. The patient died one month after diagnosis from a refractory septic shock with multiple organ failure. A molecular identification of isolate, based on partial $\beta$-tubulin and calmodulin genes, was performed and identified A. pseudodeflectus.

Conclusions: Our case raises the question of pathogenicity of this species, which belongs to Aspergillus section Usti and is genetically and morphologically very close to Aspergillus calidoustus that was previously reported in human transplant recipients.

Keywords: Aspergillosis, Liver transplantation, Aspergillus pseudodeflectus, Molecular identification, Azoles resistance

\section{Background}

Invasive aspergillosis (IA) has been reported in 1-15\% of organ transplant recipients [1-4]. In liver transplant recipients, it is the second most common invasive fungal infection (IFI) after candidiasis with a rate of $1-9.2 \%$ [4]. Aspergillosis is usually associated with high mortality ( 83 to $88 \%$ ) [1] and is most commonly caused by Aspergillus fumigatus [2]. Other non-fumigatus

\footnotetext{
* Correspondence: francoise.botterel@aphp.fr

This work was presented in part at the "Advances against Aspergillosis" (Manchester, March 2016) and at "ECCMID Congress" (Amsterdam, April 2016). 'Unité de Parasitologie-Mycologie, Département de Virologie, BactériologieHygiène, Parasitologie-Mycologie, DHU VIC, CHU Henri Mondor, AP-HP, Créteil, France

2EA Dynamyc UPEC, ENVA, Faculté de Médecine de Créteil, Créteil, France Full list of author information is available at the end of the article
}

Aspergillus species are currently emerging as substantial cause of invasive aspergillosis [5-8]. Thus, identification of the species type appears to be important due to the variable susceptibility of the members of genus Aspergillus to antifungal drugs [8-11]. The current taxonomy of Aspergillus showed cryptic species, of a single section, which are morphologically indistinguishable [12] yet may have different antifungal susceptibilities with higher minimum inhibitory concentrations (MIC) [9, 12-15]. The phylogenetic relationship between species of Aspergillus is analyzed by sequencing $\beta$-tubulin and calmodulin encoding genes regions [16].

Cryptic species from section Usti such as A. ustus, A. calidoustus, and $A$. granulosus are reported as an emerging cause of invasive aspergillosis [7, 17-20]. However, $A$.

(c) The Author(s). 2018 Open Access This article is distributed under the terms of the Creative Commons Attribution 4.0 International License (http://creativecommons.org/licenses/by/4.0/), which permits unrestricted use, distribution, and 
pseudodeflectus, another species of section Usti [21, 22], has never been reported as a causative agent of human aspergillosis. We report here the first case of invasive pulmonary aspergillosis induced by $A$. pseudodeflectus in a liver transplant recipient.

\section{Case presentation}

A 64-year-old woman known to have cirrhosis secondary to Hepatitis $\mathrm{C}$ was transplanted in our center to treat drug-induced fulminant hepatitis failure. The patient received a standard post-op immunosuppressive protocol (including corticosteroids, tacrolimus, and mycophenolate mofetil).

She also received caspofungin $(70 \mathrm{mg}$ at day 1 then $50 \mathrm{mg} /$ day) according to ESCMID recommendations as targeted prophylaxis against IA during 15 days [23]. The early post-operative period was associated with hemorrhagic episodes and peri-hepatic hematoma requiring several re-interventions whilst maintaining the antifungal prophylactic treatment. From post-operative day (POD) 31, the patient developed several septic shocks caused by Enterococcus faecium, Escherichia coli, and Candida glabrata, and all were treated by broad spectrum antibiotics and caspofungin was reintroduced.

On POD 63, the patient got fever resistant to antibiotics. Her chest CT-scan showed right-sided pleural effusion with passive atelectasis and alveolar opacity. Broncho-alveolar lavage (BAL) was performed and its direct examination displayed Aspergillus-like branched hyphae. At the same time, galactomannan (GM) antigen index (Platelia Aspergillus, BioRad) and (1-3)- $\beta$-D-glucan (BDG) (Cape Code) in serum, which were previously negative, became positive (GM antigen index $>6$ (threshold index: 0.5), $\mathrm{BDG}=234 \mathrm{pg} / \mathrm{mL}$ (threshold value: $80 \mathrm{pg} / \mathrm{mL}$ )). Aspergillus real-time PCR (qPCR), based on a target of 67-bp DNA fragment specific to the multicopy gene encoding the $28 \mathrm{~S}$ rRNA of $A$. fumigatus, was positive in serum (Cq value $=35$ ) [24]. Eventually, based upon data from the European Organization for Research and Treatment of Cancer/Mycoses Study Group (EORTC/MSG) [25], the patient was classified as having a probable IFI. Caspofungin was then switched to voriconazole (200 $\mathrm{mg}$ twice/day). On Sabouraud media, at $37^{\circ} \mathrm{C}$, the culture of BAL showed growth of several greenish to brownish colonies of filamentous fungi with a powdery aspect. Macroscopic examination revealed brown colonies on Malt media and surrounded by a white mycelium. The reversed side of the colonies was yellow. On Czapek Yeast Autolysated Agar (CYA) media, the detected colonies were much greener in color with velvety texture. Microscopic examination of the colonies showed Aspergillus biseriate conidial heads with curved conidiophores (Fig. 1). On the basis of these macroscopic and microscopic examinations, the species can be suggested but must be confirmed by molecular identification. The follow-up GM antigen index, even with voriconazole, remained positive (index $>6$ at POD 65 and 70). Antifungal drug susceptibilities were determined by Etest on RPMI medium supplemented with $2 \%$ glucose. MICs were read at $48 \mathrm{~h}$ of incubation at $35^{\circ} \mathrm{C}$. MICs of amphotericin $\mathrm{B}$, itraconazole, voriconazole, posaconazole, micafungin, and caspofungin were $0.75 \mu \mathrm{g} / \mathrm{mL}, 12 \mu \mathrm{g} / \mathrm{mL}$, $4 \mu \mathrm{g} / \mathrm{mL}, 6 \mu \mathrm{g} / \mathrm{mL}, 0.016 \mu \mathrm{g} / \mathrm{mL}$, and $0.5 \mu \mathrm{g} / \mathrm{mL}$, respectively. Since the antifungal susceptibility revealed elevated MICs to azoles, voriconazole was then switched to liposomal amphotericin B. Additionally the results of EUCAST method confirmed the high MICs to azoles. On POD 81, the patient died from multiple organs failure and refractory septic shock secondary to pneumonia. Autopsy was not performed.

A molecular identification of this Aspergillus was performed. Complete genomic DNA was extracted from a mature subculture on Sabouraud agar using QIAamp DNA Blood Mini Kit (Qiagen Sciences Ing.) after a step of bead beading in MagNA Lyser Instrument (Roche). The rDNA of partial $\beta$-tubulin and calmodulin genes were amplified as described by Samson et al. [16]. Sequencing reactions were carried out for both strands. When compared with the partial calmodulin gene sequences available in the NCBI database, the highest identity was obtained with A. pseudodeflectus NRRL 278 strain (Genbank accession number EF652368.1) and NRRL 6135 strain (Genbank accession number EF652419.1) [16] with nucleotide identity rates of 100 and $99 \%$, respectively over a sequence length of $573 \mathrm{bp}$. For the partial $\beta$-tubulin sequences, identity rates of $99 \%$ were obtained with both strains, NRRL 278 (Genbank accession number EF652280.1) and CBS 596.65 (Genbank accession number EF591732.1). Phylogenetic trees of these two sequences, alone and combined, were built with the MEGA 6.05.1 software [26]. The neighbor-joining method, using the Kimura two-parameter model with 1000 bootstraps replications, was applied to each data set. The sequence relatedness of our strain with the species strains type of section Usti is shown in Fig. 2.

\section{Discussion and conclusion}

We report the first case of IA caused by A. pseudodeflectus. This species was first described by Samson and Mouhacca in 1975 in Egyptian desert soil samples [27]. A. pseudodeflectus belongs to Aspergillus section Usti $[21,22]$. This section includes more than 20 species. $A$. calidoustus was isolated from air and water distribution systems in hospital environment, after some clinical cases [28-30]. Taxonomy of this section keeps evolving as two new species have recently been reported [31]. Outbreaks have already been reported, although the infection source was not clearly identified $[18,32]$. No data are available on environmental or aerial distribution of $A$. 

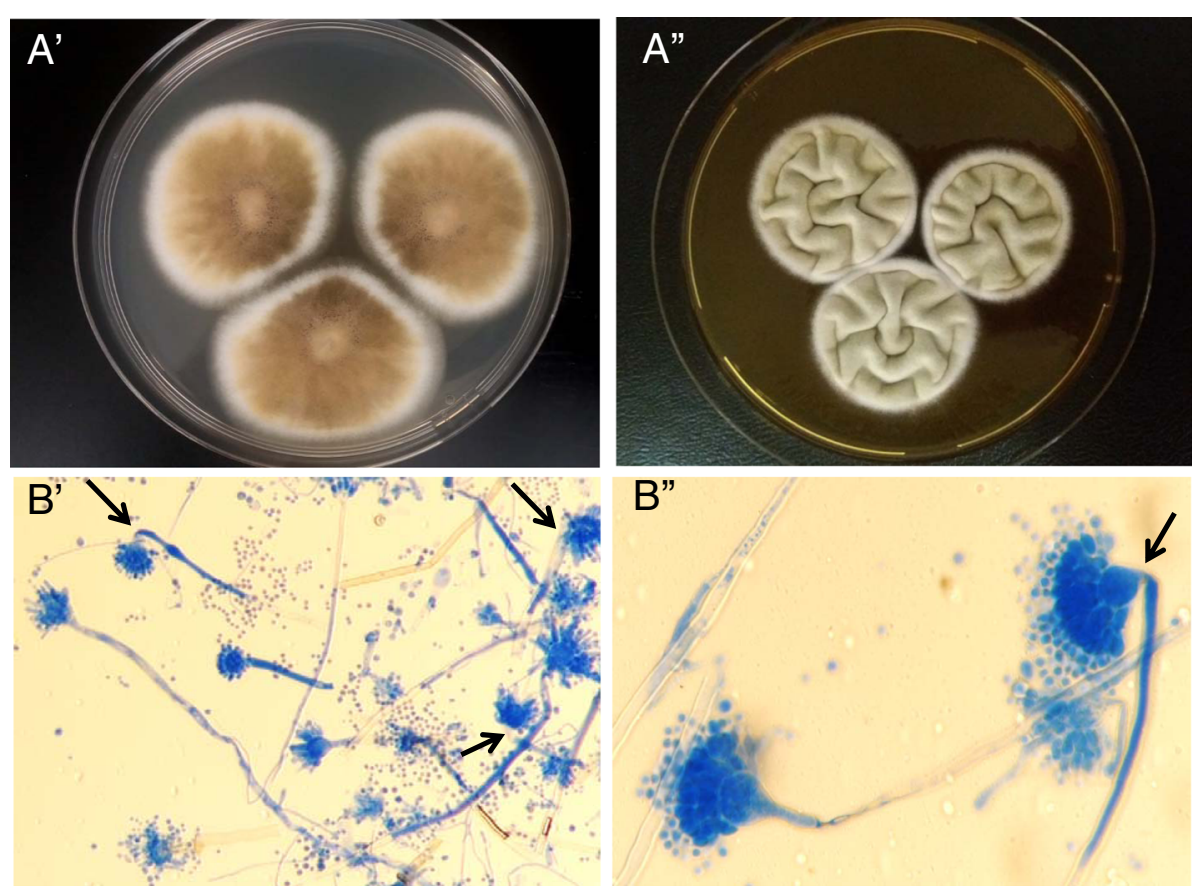

Fig. 1 Aspergillus pseudodeflectus isolated from BAL. a. Colony at $25^{\circ} \mathrm{C}$ after 7 days. A'. Malt Extract Agar (MEA). A". Czapek Yeast Autolysate Agar $($ CYA $)+20 \%$ sucrose. B. Microscopic aspect with blue lactophenol staining (CYA). b'. Magnification $\times 200$. B". Magnification $\times 1000$. Arrows show curved conidiophores

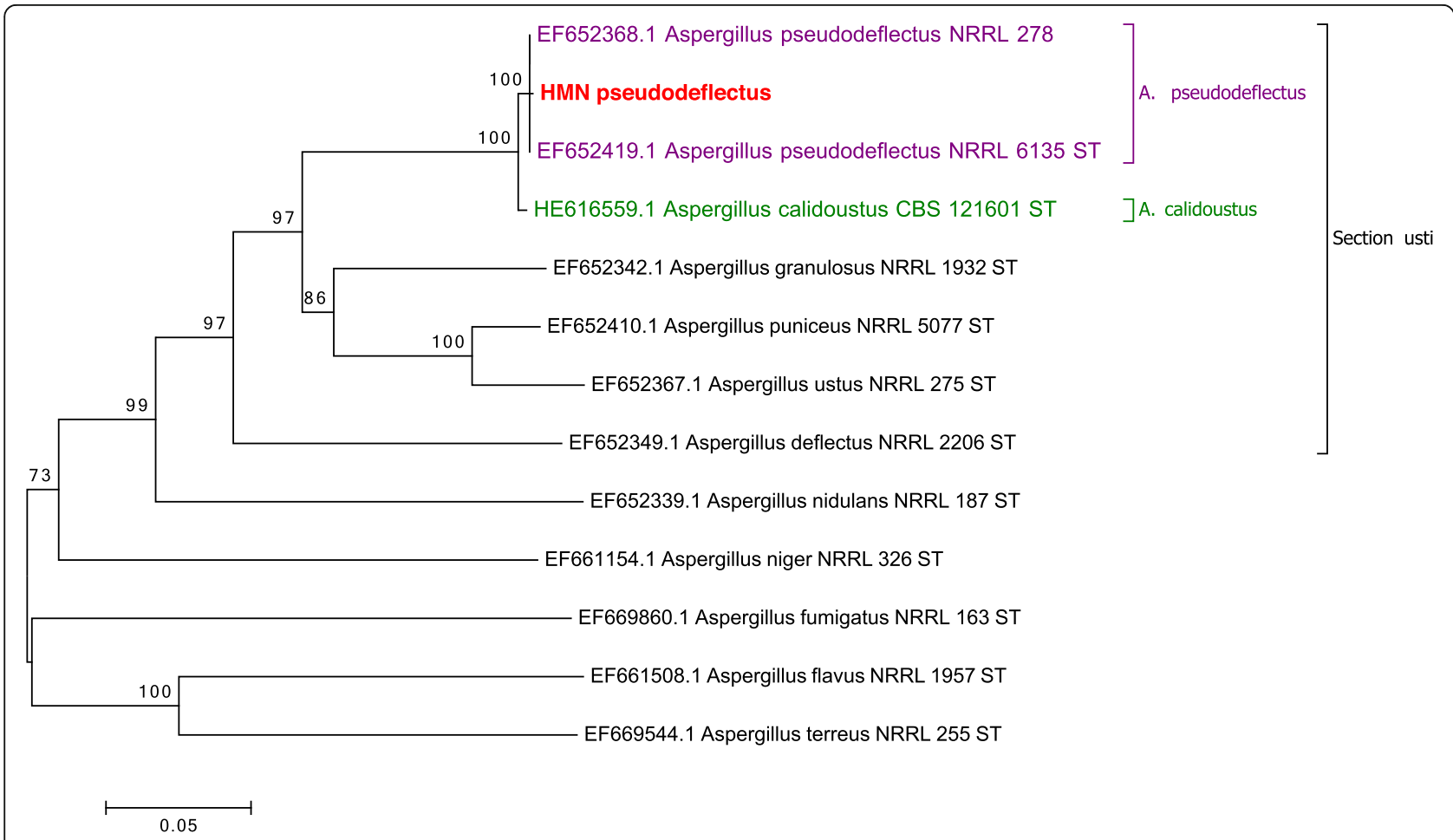

Fig. 2 Neighbour-joining tree based on $\beta$-tubulin and calmodulin genes sequence data of HMN Aspergillus pseudodeflectus. Numbers above the nodes represent bootstrap values. These values were generated from 1000 replicates. The bar length represents the specified genetic distance. Only values above $70 \%$ are indicated 
pseudodeflectus. In our patient, inhalation is probably the source of infection yet no air sampling was performed in the surgical department and no other similar case was declared in the same ward.

Aspergillus section Usti species are rarely pathogenic but can be opportunistic agents. The immunocompromised patients affected by these fungi are hematopoietic stem cells transplant (HSCT), lung transplant, and heart transplant patients $[6,17,19,33-37]$. Pulmonary and cutaneous infections are the most common complaints $[6$, $18,33-35,37]$. GM index can be positive in patients infected by Aspergillus species of this section [38] and the clinical evolution and our case confirms these data. Aspergillus PCR and BDG were also positive in our patient but no data are available in the literature to validate these diagnostic tools in aspergillosis induced by section $U$ sti.

Molecular identification is recommended to avoid false identifications because species within a single section cannot be morphologically [39] distinguished from each other [12] . Previous cases of IA caused by A. ustus were misidentified [21], mostly as A. calidoustus [40]. The latter was included as a new species in 2008, and ever since it has been the most commonly reported cause of IA in this section [21]. In contrast to A. ustus, which cannot grow at $37^{\circ} \mathrm{C}, A$. pseudodeflectus and A. calidoustus can grow at $37^{\circ} \mathrm{C}$, and this could explain their human pathogenicity $[22,41]$. A. pseudodeflectus has never been described in human pathology but it has probably been underestimated before the establishment of molecular identification.

Aspergillus molecular identification is based on sequencing partial $\beta$-tubulin and calmodulin genes [39]. Sequencing of ITS regions does not enable clear differentiation between the species of a single section. Our results (Fig. 2) show that our isolate of A. pseudodeflectus is closely related to $A$. calidoustus. Other non-molecular parameters can be used to distinguish $A$. pseudodeflectus from A. calidoustus, like a negative Ehrlich reaction and curved conidiophores, as described in our case [41] .

To our knowledge, there are few data on antifungal susceptibilities of section Usti. A. calidoustus has been reported as intrinsically resistant to azoles $[8,14,21$, 42-44], and this imposes management difficulty since voriconazole is the first line reference treatment of aspergillosis [45]. Echinocandins and amphotericin B MICs seem to be more variable [21, 42]. Antifungal susceptibilities of $A$. pseudodeflectus are not well known but the MICs calculated on our isolate suggest that it is resistant to azoles like the other species of complex Usti. Although, echinocandins and amphotericin B MICs of our isolate were relatively low, our patient developed aspergillosis while being on caspofungin prophylaxis treatment. The treatment was switched first to voriconazole and then to liposomal amphotericin B but the patient did not recover. In a review on IA due to $A$. calidoustus in HSCT patients treated with liposomal amphotericin B, a poor outcome was also observed [18]. This suggests that Amphotericin B may not be very effective. Interestingly, terbinafine showed low MIC to A. calidoustus [43] but this treatment is difficult to manage in immunocompromised and critical care patients.

Our case reports an invasive pulmonary aspergillosis in a liver transplant recipient caused by $A$. pseudodeflectus, a species that is newly described in human diseases and presented resistant to azoles. The use of molecular tests is important for Aspergillus identification because of its cryptic species and potential antifungal resistance which cannot be detected by routine techniques. Other studies on epidemiology, diagnostic tools, and antifungal susceptibility of Aspergillus section Usti are needed.

\section{Abbreviations

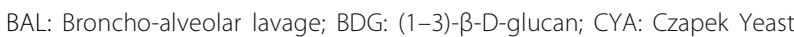 Autolysated Agar; GM: Galactomannan; HSCT: Hematological stem cells transplantation; IA: Invasive aspergillosis; IFI: Invasive fungal infection; MIC: Minimum inhibitory concentrations; POD: Post-operative day}

\section{Acknowledgements}

We thank Dr. Suhad Assad for her critical linguistic reviewing, Jean Marc Costa for the nucleotide sequences analyzes and Jean-Claude Merle for collecting the clinical data.

Funding

No funding has been obtained for this work.

Availability of data and materials

The partial tubulin and calmodulin sequences generated and analyzed during the current study were submitted to Genebank under accession numbers MH820414 and MH844380 respectively.

\section{Authors' contributions}

NAA and FB designed and conceptualized the work. EL collected and interpreted the clinical data. NAA, FF and ED carried out, analyzed ant interpreted the microbiological data. JBM, $\mathrm{SI}$ and ED carried out, analyzed ant interpreted the molecular data. NAA, EL, SI and FB wrote the manuscript. JBM, FF and ED revised the manuscript critically for important content. All authors read and approved the final manuscript.

\section{Ethics approval and consent to participate}

This study was carried out in compliance with the Helsinki declaration. All liver transplants of our institution have read and approved the hospital welcome book, which states that their biological samples, after use, may be used for publication in the context of biological collections (except for genetic analyzes). Henri Mondor ethical committee approved the study protocol and database has been declared to the Commission Nationale de l'Informatique et des Libertés (CNIL) $\left(n^{\circ} 1,699,340\right)$.

\section{Consent for publication}

Written informed consent was obtained from the patient's family for the publication of this manuscript. No images or videos relating to the individual person were included in this article.

\section{Competing interests}

ED has received grants from Gilead, Ferrer, and Biorad, and payment for lectures from Gilead, MSD, and Schering. ED has also been a consultant for Astellas and Innothera. FB received grants from Astellas, and payment for lectures from Merck. NAA, EL, JBM, SI, FF, declare no conflict of interest. 


\section{Publisher's Note}

Springer Nature remains neutral with regard to jurisdictional claims in published maps and institutional affiliations.

\begin{abstract}
Author details
'Unité de Parasitologie-Mycologie, Département de Virologie, BactériologieHygiène, Parasitologie-Mycologie, DHU VIC, CHU Henri Mondor, AP-HP, Créteil, France. ${ }^{2}$ EA Dynamyc UPEC, ENVA, Faculté de Médecine de Créteil, Créteil, France. ${ }^{3}$ Réanimation Digestive et Hépato-biliaire, Service d'Anesthésie et des Réanimations Chirurgicales, CHU Henri Mondor, AP-HP, Créteil, France. ${ }^{4}$ Service de Parasitologie-Mycologie, CHU Pitié Salpêtrière, AP-HP, Paris, France. ${ }^{5}$ Université Paris-Descartes, Faculté de Médecine, Unité de Parasitologie-Mycologie, Service de Microbiologie, Hôpital Européen Georges Pompidou, AP-HP, Paris, France.
\end{abstract}

Received: 17 July 2018 Accepted: 19 November 2018

Published online: 12 December 2018

\section{References}

1. Singh N, Husain S. The AST infectious diseases Community of Practice. Invasive aspergillosis in solid organ transplant recipients. Am J Transplant. 2009:9:S180-91.

2. Neofytos D, Treadway S, Ostrander D, Alonso CD, Dierberg KL, Nussenblatt $V$, et al. Epidemiology, outcomes, and mortality predictors of invasive mold infections among transplant recipients: a 10-year, single-center experience. Transpl Infect Dis Off J Transplant Soc. 2013;15(3):233-42.

3. Barchiesi F, Mazzocato S, Mazzanti S, Gesuita R, Skrami E, Fiorentini A, et al. Invasive aspergillosis in liver transplant recipients: epidemiology, clinical characteristics, treatment, and outcomes in 116 cases. Liver Transpl. 2015; 21(2):204-12.

4. Romero FA. Infections in liver transplant recipients. World J Hepatol. 2011; 3(4):83.

5. Walter J, Sobottka I, Rogiers X, Broering D, Fischer L. Invasive aspergillosis caused by aspergillus terreus in a living donor liver transplant recipient successfully treated by caspofungin. Mycoses. 2011;54(4):e220-2.

6. Balajee SA, Kano R, Baddley JW, Moser SA, Marr KA, Alexander BD, et al. Molecular identification of aspergillus species collected for the transplant-associated infection surveillance network. J Clin Microbiol. 2009;47(10):3138-41.

7. Stiller MJ, Teperman L, Rosenthal SA, Riordan A, Potter J, Shupack JL, et al. Primary cutaneous infection by aspergillus ustus in a 62-year-old liver transplant recipient. J Am Acad Dermatol. 1994;31(2 2):344-7.

8. Baddley JW, Marr KA, Andes DR, Walsh TJ, Kauffman CA, Kontoyiannis DP, et al. Patterns of susceptibility of aspergillus isolates recovered from patients enrolled in the transplant-associated infection surveillance network. J Clin Microbiol. 2009;47(10):3271-5.

9. Howard SJ. Multi-resistant aspergillosis due to cryptic species Mycopathologia. 2014;178(5-6):435-9.

10. Balajee SA, Gribskov JL, Hanley E, Nickle D, Marr KA. Aspergillus lentulus sp. nov., a new sibling species of a. fumigatus. Eukaryot Cell. 2005:4(3):625-32.

11. Lass-Flörl C. In vitro susceptibility testing in aspergillus species: an update. Future Microbiol. 2010;5(5):789-99.

12. Peterson SW. Phylogenetic analysis of aspergillus species using DNA sequences from four loci. Mycologia. 2008;100(2):205-26.

13. Howard SJ, Harrison E, Bowyer P, Varga J, Denning DW. Cryptic species and azole resistance in the aspergillus Niger complex. Antimicrob Agents Chemother. 2011;55(10):4802-9.

14. Alastruey-Izquierdo A, Mellado E, Cuenca-Estrella M. Current section and species complex concepts in aspergillus: recommendations for routine daily practice. Ann N Y Acad Sci. 2012;1273(1):18-24.

15. Alcazar-Fuoli L, Mellado E, Alastruey-Izquierdo A, Cuenca-Estrella M, Rodriguez-Tudela JL. Aspergillus section Fumigati: antifungal susceptibility patterns and sequence-based identification. Antimicrob Agents Chemother. 2008:52(4):1244-51.

16. Samson RA, Visagie CM, Houbraken J, Hong S-B, Hubka V, Klaassen CHW, et al. Phylogeny, identification and nomenclature of the genus aspergillus. Stud Mycol. 2014;78:141-73.

17. Florescu DF, Iwen PC, Hill LA, Dumitru I, Quader MA, Kalil AC, et al. Cerebral aspergillosis caused by aspergillus ustus following orthotopic heart transplantation: case report and review of the literature. Clin Transpl. 2009. 23(1):116-20.
18. Panackal AA, Imhof A, Hanley EW, Marr KA. Aspergillus ustus infections among transplant recipients. Emerg Infect Dis. 2006;12(3):403-8.

19. Sutton DA, Wickes BL, Romanelli AM, Rinaldi MG, Thompson EH, Fothergill AW, et al. Cerebral aspergillosis caused by aspergillus granulosus. J Clin Microbiol. 2009:47(10):3386-90.

20. Peláez T, Alvarez-Pérez S, Mellado E, Serrano D, Valerio M, Blanco JL, et al. Invasive aspergillosis caused by cryptic aspergillus species: a report of two consecutive episodes in a patient with leukaemia. J Med Microbiol. 2013; 62(3):474-8.

21. Varga J, Houbraken J, Van Der Lee HAL, Verweij PE, Samson RA. Aspergillus calidoustus sp. nov., causative agent of human infections previously assigned to aspergillus ustus. Eukaryot Cell. 2008;7(4):630-8.

22. Samson RA, Varga J, Meijer M, Frisvad JC. New taxa in aspergillus section Usti. Stud Mycol. 2011;69(1):81-97.

23. Gavaldà J, Meije Y, Fortún J, Roilides E, Saliba F, Lortholary O, et al. Invasive fungal infections in solid organ transplant recipients. Clin Microbiol Infect. 2014;20(7):27-48

24. Challier S, Boyer S, Abachin E, Berche P. Development of a serum-based Tagman real-time PCR assay for diagnosis of invasive aspergillosis. J Clin Microbiol. 2004;42(2):844-6.

25. Pauw BD, Walsh TJ, Donnelly JP, Stevens DA, Edwards JE, Calandra T, et al. Revised definitions of invasive fungal disease from the European Organization for Research and Treatment of cancer/invasive fungal infections cooperative group and the National Institute of Allergy and Infectious Diseases mycoses study group (EORTC/MSG) consensus group. Clin Infect Dis. 2008;46(12):1813-21.

26. Tamura K, Stecher G, Peterson D, Filipski A, Kumar S. MEGA6: molecular evolutionary genetics analysis version 6.0. Mol Biol Evol. 2013;30(12):2725-9.

27. Samson RA, Mouchacca J. Additional notes on species of aspergillus, Eurotium and Emericella from Egyptian desert soil. Antonie Van Leeuwenhoek. 1975;41(3):343-51.

28. Khan Z, Ahmad S, Joseph L. Aerial prevalence of aspergillus calidoustus isolates in and around a tertiary Care Hospital in Kuwait and Assessment of their pathogenicity. J Clin Microbiol. 2014;52(9):3402-5.

29. Hageskal G, Kristensen R, Fristad RF, Skaar I. Emerging pathogen aspergillus calidoustus colonizes water distribution systems. Med Mycol. 2011:6:588-93.

30. Oliveira BR, Crespo MTB, San Romão MV, Benoliel MJ, Samson RA, Pereira VJ. New insights concerning the occurrence of fungi in water sources and their potential pathogenicity. Water Res. 2013;47(16):6338-47.

31. Jurjevic Z, Peterson SW. Aspergillus asper and aspergillus collinsii, two new species from aspergillus section Usti. Int J Syst Evol Microbiol. 2016;66(7): 2566-72. https://doi.org/10.1099/ijsem.0.001094.

32. Saracli MA, Mutlu FM, Yildiran ST, Kurekci AE, Gonlum A, Uysal Y, et al. Clustering of invasive aspergillus ustus eye infections in a tertiary care hospital: a molecular epidemiologic study of an uncommon species. Med Mycol. 2007;45(4):377-84

33. Cabada MM, Nishi SP, Lea AS, Schnadig V, Lombard GA, Lick SD, et al. Concomitant pulmonary infection with Nocardia transvalensis and aspergillus ustus in lung transplantation. J Heart Lung Transplant Off Publ Int Soc Heart Transplant. 2010;29(8):900-3.

34. Vagefi PA, Cosimi AB, Ginns LC, Kotton CN. Cutaneous aspergillus ustus in a lung transplant recipient: emergence of a new opportunistic fungal pathogen. J Heart Lung Transplant. 2008;27(1):131-4.

35. Nakai K, Kanda Y, Mineishi S, Hori A, Chizuka A, Niiya H, et al. Primary cutaneous aspergillosis caused by aspergillus ustus following reducedintensity stem cell transplantation. Ann Hematol. 2002;81(10):593-6.

36. Pavie J, Lacroix C, Hermoso DG, Robin M, Ferry C, Bergeron A, et al. Breakthrough disseminated aspergillus ustus infection in allogeneic hematopoietic stem cell transplant recipients receiving voriconazole or caspofungin prophylaxis. J Clin Microbiol. 2005;43(9):4902-4.

37. Verweij PE, van den Bergh MF, Rath PM, de Pauw BE, Voss A, Meis JF. Invasive aspergillosis caused by aspergillus ustus: case report and review. J Clin Microbiol. 1999;5:1606-9.

38. Bretagne S, Marmorat-Khuong A, Kuentz M, Latgé J-P, Bart-Delabesse E, Cordonnier C. Serum aspergillus galactomannan antigen testing by sandwich ELISA: practical use in neutropenic patients. J Inf Secur. 1997;35(1):7-15

39. Balajee SA, Borman AM, Brandt ME, Cano J, Cuenca-Estrella M, Dannaoui E, et al. Sequence-based identification of aspergillus, fusarium, and Mucorales species in the clinical mycology laboratory: where are we and where should we go from Here? J Clin Microbiol. 2009;47(4):877-84. 
40. Seroy J, Antiporta P, Grim SA, Proia LA, Singh K, Clark NM. Aspergillus calidoustus case series and review of the literature. Transpl Infect Dis. 2017; 19(5):e12755.

41. Houbraken J, Due M, Varga J, Meijer M, Frisvad JC, Samson RA. Polyphasic taxonomy of aspergillus section Usti. Stud Mycol. 2007;59:107-28.

42. Alastruey-Izquierdo A, Mellado E, Peláez T, Pemán J, Zapico S, Alvarez M, et al. Population-based survey of filamentous Fungi and antifungal resistance in Spain (FILPOP study). Antimicrob Agents Chemother. 2013; 57(7):3380-7.

43. Alastruey-Izquierdo A, Cuesta I, Houbraken J, Cuenca-Estrella M, Monzón A, Rodriguez-Tudela JL. In vitro activity of nine antifungal agents against clinical isolates of aspergillus calidoustus. Med Mycol. 2010;48(1):97-102.

44. Arendrup MC. Update on antifungal resistance in aspergillus and Candida. Clin Microbiol Infect. 2014;20:42-8.

45. Patterson TF, Thompson GR, Denning DW, Fishman JA, Hadley S, Herbrecht $R$, et al. Practice guidelines for the diagnosis and Management of Aspergillosis: 2016 update by the Infectious Diseases Society of America. Clin Infect Dis. 2016;63(4):e1-60.

Ready to submit your research? Choose BMC and benefit from:

- fast, convenient online submission

- thorough peer review by experienced researchers in your field

- rapid publication on acceptance

- support for research data, including large and complex data types

- gold Open Access which fosters wider collaboration and increased citations

- maximum visibility for your research: over $100 \mathrm{M}$ website views per year

At $\mathrm{BMC}$, research is always in progress.

Learn more biomedcentral.com/submissions 